\title{
Human Development through the Lens of Digital Literacy
}

\author{
Debbra Toria Nipo \\ Faculty of Business, Economics and Accountancy \\ Universiti Malaysia Sabah, Malaysia \\ E-mail: debbratoria@ums.edu.my \\ Jaratin Lily \\ Faculty of Business, Economics and Accountancy \\ Universiti Malaysia Sabah, Malaysia
}

Sidah Idris

Faculty of Business, Economics and Accountancy

Universiti Malaysia Sabah, Malaysia

\author{
Saizal Pinjaman \\ Faculty of Business, Economics and Accountancy \\ Universiti Malaysia Sabah, Malaysia
}

Imbarine Bujang

Faculty of Business and Management, Universiti Teknologi MARA, Malaysia

Received: June 16, 2020 Accepted: July 2, 2020 Published: July 25, 2020

doi:10.5296/ber.v10i3.17183 URL: https://doi.org/10.5296/ber.v10i3.17183

\section{Abstract}

Digital inclusion has now become not only a matter of technological adoption, but the ability 
to use technologies where individuals are to possess necessary skills to make effective use of digital technologies. In this regard, digital literacy is seen as a crucial enabler for individuals to take advantage of digital opportunities as well as to engage in digital activities. Building on the importance of digital literacy, this study therefore attempts to assess the role of Internet usage and digital literacy on human development, which is proxied by the Human Development Index (HDI). Using a panel dataset covering 38 countries over a 4-year time span from 2015 to 2018, results of regression analysis indicate that both Internet usage and digital literacy emerge with significant and positive relationships with HDI. This evidence suggests that the high number of Internet users and high level of digital literacy are important means for promoting human development. Additional moderation analysis between Internet usage and digital literacy also produces a positive and significant interaction effect, which subsequently implies that digital literacy is an essential skill in enhancing effective usage of the Internet towards achieving greater socioeconomic well-being.

Keywords: Human development, Technological impact, Digital literacy

JEL Classification: I31, O33

\section{Introduction}

The 1990s saw a change in the landscape of development theory when the concept of human development was introduced as progress towards greater human well-being (United Nations Development Programme (UNDP), 1990). Drawing substantially from Amartya Sen's work on his capability approach, human development highlights the importance of ends (decent standard of living) over importance of means (income per capita) (Sen, 1985). In other words, human development is concerned with advancing the richness of human life, rather than the richness of the economy in which people live. Ultimately, this goes back to the key objective of development, which is to create an enabling environment for people to enjoy long, healthy and creative lives (Alkire \& Deneulin, 2009). Building upon this idea, the Human Development Index (HDI) is devised by the UNDP to measure the levels of social and economic developments of different countries. The HDI provides a single index that captures three key dimensions of human development: a long and healthy life, access to knowledge and a decent standard of living (Roser, 2014).

Knowledge is rooted at the very core of development process. It is through knowledge that human beings become aware of opportunities and challenges, formulate responses, make decisions and initiate organised actions (Jacobs \& Asokan, 2000). No matter how great the opportunity or how dire the necessity is, without that knowledge, no adaptive response occurs. In today's increasingly complex and competitive world, information and communication technology (ICT) is viewed as the key enabler to such knowledge creation and dissemination (Suharyanto \& Gunawan, 2015). Recent advancements in ICT not only has made it possible to have prompt access to the wealth of information and knowledge available through the Internet, it also can bring about improvements in healthcare provision and ultimately, better quality of life. One of the evidences that support the positive impact ICT usage can have on human well-being can be found in a study by Çaglayan-Akay and Van (2017). Their study used seven independent variables namely Internet users, rural population, gross domestic 
product (GDP), life expectancy at birth, health expenditure and share of expected years of schooling, to be tested for their impacts towards human development, which was proxied by the HDI. Findings of their study indicated that GDP, health expenditure, the share of expected years of schooling and Internet users were the variables that have positive influence on HDI, in both short and long run periods. It is worth noting here that their study included an ICT variable (Internet users), whose positive relationship indicated importance of ICT in promoting human development. In light of these important contributions, ICT entails a set of human capabilities that can be harnessed and fostered to further human development.

Digital literacy has become one of the increasingly essential skills and capabilities needed to participate fully, effectively and equally in this digital world. Not only does it serve as a catalyst for effective lifelong learning (Alazie, Devi \& Ebabye, 2019; Jose, 2016), digital literacy is also crucial to closing the digital gap and promote inclusion for all. This is in line with achieving a number of the United Nation's Sustainable Development Goals (SDGs), including SDG4 which seeks to "ensure inclusive and equitable quality education and to promote lifelong learning opportunities for all” (United Nations (UN), 2015). Similar to the traditional literacy and numeracy skills, digital literacy has become much more than just the ability to handle computers; it also means knowing how to leverage digital tools to process and retrieve ideas as well as engage in knowledge creation and sharing with diverse people from around the world (Vega, 2011). According to Kaparti (2011), digital literacy is an umbrella term for important digital skills clusters whose names are often used interchangeably, yet they carry slightly different meanings from each other. These skill clusters are: (i) ICT literacy, which refers to a set of user skills that enables active participation on digital platforms; (ii) technological literacy (previously known as computer literacy), which involves broader understanding of digital technology and includes both user and technical computing skills; and (iii) information literacy, which entails the ability to locate, identify, retrieve, process and use digital information optimally.

While the opportunities that accompany technological developments are immense, the emerging technologies present a significant challenge too. The International Telecommunication Union (ITU) (2019) predicted that in the coming years, a large skills gap would emerge where there will be tens of millions of jobs for those with advanced digital skills, and these job openings may go unfilled by 2020 due to shortage of qualified people with sufficient job-relevant digital skills to fill the vacancies. In addition to this skills gap, technological changes may also bring about mass unemployment and growing inequality (World Economic Forum, 2016). To effectively respond to the technological changes, digital literacy becomes even more essential and is considered a basic requirement for all to participate fully in the digital economy and society. To date, a considerable body of research has sought to determine the impact of ICT (Bahrini \& Qaffas, 2019; Toader, Firtescu, Roman \& Anton, 2018; Das, Khan \& Chowdhury, 2016) and impact of literacy (Njoku, 2011; Coulombe \& Tremblay, 2006) on economic growth and development. While this study provides several important insights regarding factors affecting human development, it particularly sheds light into the possible influence of digital literacy and whether or not it moderates the relationship between Internet usage and human development. In addition, 
research on the role digital literacy plays in influencing human development is notably lacking. This relationship is conceptually intriguing as the study aims to bridge several important domains of macroeconomic research (technology, literacy and development) by introducing the idea of a possible linkage between them. This study, therefore, seeks to fill this gap by investigating the influence of Internet usage and digital literacy towards human development. The present findings demonstrate that, while high levels of both Internet usage and digital literacy improve human development, the relationship between Internet usage and human development becomes stronger when digital literacy is present. Therefore, the evidence from this study is also intended to make contribution to the body of literature particularly in regard to digital literacy and human development.

\section{Literature Review}

The economy is traditionally measured either in terms of its growth or development. In theorizing economic growth, the economy is generally viewed as a machine that produces economic output as function of inputs such as labor, land and equipment (Smith, 1776; Ricardo, 1817; Solow, 1956). To put it plainly, increase in economic output (due to greater number of inputs or improved efficiency through use of technology or innovation) signals economic growth. Economic development on the other hand, differs from economic growth as it entails a fundamental transformation of an economy (Schumpeter, 1962). While economic growth means putting more people to work within an existing economic framework, economic development is aimed at altering that framework so that people work more productively, and the economy subsequently shifts toward higher value-added activities in achieving greater prosperity and higher quality of life (Feldman, Hadjimichael, Lanahan \& Kemeny, 2015).

Human development, meanwhile, is defined as an expansion of capacity that creates the potential to improve human lives (Sen, 1999). According to Alkire and Deneulin (2009), both economic and human developments are closely intertwined as the aspect of human development touches on every element of economic development. The concept of human development sought to diverge from the revenue-centered concept to a people- and skill-oriented system based on capabilities. It is evident that in this human development paradigm, human beings are regarded as the most significant and valuable assets of the nations (Gokmen \& Turen, 2013). Though achievement of high growth targets is of great importance, empowering people to have more alternatives and to access knowledge, better nutrition and health services are also equally crucial. This has led to the creation of HDI to provide a more encompassing measure of development. The HDI combines proxies for three essential components namely health, knowledge and standard of living (UNDP, 1990). Health is represented by life expectancy, education by literacy and school enrolment, and standard of living by gross domestic product (GDP) per capita.

In a more recent study, De La Hoz, Camacho-Ballesta, Tamayo-Torres and Buelvas-Ferreira (2019) conducted an international analysis of how use and adoption of ICT by three different parties - individuals, enterprises and governments - affects human development. Findings of their study indicated that the individual use of ICT has a positive and significant impact on 
human development, regardless of a country's level of development. Moreover, Ejemeyovwi, Osabuohien, Johnson and Bowale (2019) who particularly investigated the influence of Internet usage and innovation on human development, found that Internet usage, innovation and their interaction have significant and positive relationship with human development. Muchdie (2016) meanwhile, employed a path model analysis to examine both direct and indirect impacts of technological progress on human development in Indonesia. Findings in his study showed that technological progress had positive impact on human development, through poverty reduction and economic growth. This relationship between technological progress and human development - although indirect - suggests that higher technological progress is associated with higher human development in Indonesia during the period under review. As asserted by Hameed (2007), ICT for human development does not merely revolve around the technology, but it is also about the people using the technology itself to meet some of their basic needs. This consequently sheds light on the meaning and growing importance of digital literacy.

The rapidly evolving technological environment and knowledge-driven economy demands a good command of digital literacy. While much has been written about digital literacy, consensus on a single definition of the term appears to be elusive. Initially, the term digital literacy was built around the ideas of information literacy and computer literacy, that originated largely to describe sets of specific skills and competencies required for obtaining and handling information in computerized form (Bawden, 2008). Gilster (1997) moved away from such limited "technical skills" view of digital literacy by defining it as the ability to understand and use information in multiple formats from various digital sources, through four core competencies: Internet searching, hypertext navigation, knowledge assembly, and content evaluation. Similarly, Martin's (2006) take on digital literacy also recognizes not only the need for mastering electronic tools, but it is also about integrating other various literacies and skill sets such as ICT literacy, information literacy, media literacy and visual literacy. While it is well-established in the body of literature that literacy has significant positive impact on economic growth (Njoku, 2011; Coulombe \& Tremblay, 2006), not much research however has been done on investigating the role digital literacy particularly plays in influencing human development.

Therefore, this research gap provides the motivation for this study that aims to investigate whether Internet usage and digital literacy have an impact on human development in selected countries. Additionally, this study also seeks to extend its analysis in order to determine whether digital literacy plays any moderating role on the relationship between Internet usage and human development.

\section{Data and Methodology}

\subsection{Data}

In this study, a yearly panel dataset for 38 countries over a 4-year period from 2006 to 2018 is used to assess the relationship between digital literacy and HDI. These data were extracted from the World Bank database as well as from the United Nations Global Sustainable Development database. Human development serves as the dependent variable in this study, 
which is proxied by the Human Development Index (HDI). As for the independent variables, Internet usage and digital literacy are the two main independent variables to be tested for their impacts towards the HDI, alongside several other control variables. While Internet usage is proxied by the number of individuals using the Internet, the variable digital literacy is measured by a combination of several ICT skills under each of the digital skills clusters following Kaparti's (2011) definition of digital literacy.

Based on the United Nation's SDG Indicators database, these ICT skills include: (i) using basic arithmetic formula in a spreadsheet; (ii) transferring files between a computer and other devices; (iii) finding, downloading, installing and configuring software; (iv) copying or moving a file or folder; (v) using copy and paste tools to duplicate or move information within a document; (vi) sending e-mails with attached files; (vii) creating electronic presentations with presentation software; (viii) connecting and installing new devices; and (ix) writing a computer program using a specialized programming language.

\subsection{Model Specification}

Modifying the regression model adopted from Amato-Fortes, Guarnido-Rueda and Molina-Morales (2017), the regression models in this study are specified as follows:

Model 1:

$$
H D I_{i t}=\alpha_{i t}+\beta_{1} F D I_{i t}+\beta_{2} T O_{i t}+\beta_{3} U N E_{i t}+\beta_{4} I N F_{i t}+\beta_{5} I N T R_{i t}+\varepsilon_{i t}
$$

Model 2:

$$
H D I_{i t}=\alpha_{i t}+\beta_{1} F D I_{i t}+\beta_{2} T O_{i t}+\beta_{3} U N E_{i t}+\beta_{4} I N F_{i t}+\beta_{5} I N T R_{i t}+\beta_{6} D L I T_{i t}+\varepsilon_{i t}
$$

Model 3:

$$
H D I_{i t}=\alpha_{i t}+\beta_{1} F D I_{i t}+\beta_{2} T O_{i t}+\beta_{3} U N E_{i t}+\beta_{4} I N F_{i t}+\beta_{5} I N T R_{i t}+\beta_{6} L I T_{i t}+\beta_{7} I N T R_{*} D L I T_{i t}+\varepsilon_{i t}
$$

where $\quad$ HDI $=$ Human Development Index (HDI) of country $i$ year $t$

FDI $=$ Foreign direct investment $(\%$ of GDP $)$ of country $i$ year $t$

$\mathbf{T O}=$ Trade openness (\% of GDP) of country $i$ year $t$

$\mathbf{U N E}=$ Unemployment rate $(\%$ of total labor fource $)$ of country $i$ year $t$

$\mathbf{I N F}=$ Inflation (annual \%) of country $i$ year $t$

INTR = Individuals using the Internet (\% of population) of country $i$ year $t$

DLIT $=$ Proportion of youth/adults with ICT skills (\%) of country $i$ year $t$

As observed above, Model 2 is an extension of Model 1 which introduces additional variable that is digital literacy; whereas Model 3 is an extension of Model 2 with an introduction of interaction term (INTR*DLIT) between Internet usage and digital literacy. The rationale of employing these three model specifications is to observe the possible changes in parameter of other existing independent variables when the digital literacy variable and its interaction term 


\section{Macrothink

are introduced into the regression models. All of these three regression models are analysed separately using the static panel data estimation approach.

Before proceeding to the primary regression analysis, preliminary testing using the Breusch Pagan Lagrange Multiplier (BP LM) test and Hausman test is conducted to determine whether data can be pooled as well as to decide whether to employ the random effect or fixed effect estimator. This is followed by diagnostic checks that test for presence of multicollinearity, heteroskedasticity and serial correlation in the regression models, using the Variance Inflation Factor (VIF) test, Modified Wald test and Wooldridge test, respectively. If it was found that the models suffer from any of the econometric problems, the resulting static panel data estimation technique (either random effect or fixed effect) is to be performed with corrected or robust standard errors.

\section{Results and Discussion}

The Table 1 below reports statistical findings obtained from estimating three different regression models with the HDI as the dependent variable. As shown in Table 1, both $p$-values of the BP LM test and Hausman test are significant for all three regression models; where further preliminary testing of all three models favored the use of a fixed effect estimator rather than a random effect estimator. Subsequently, this study undertook several diagnostic checks to ensure robustness of all model estimations. First, the small values of Variance Inflation Factor (VIF) indicated absence of any multicollinearity between the explanatory variables in both Model 1 and Model 2. Meanwhile, the high VIF value in Model 3 can be safely ignored as it is caused by the inclusion of interaction term between two independent variables (Allison, 2012). Next, the significant $p$-values produced by the Modified Wald test and Wooldridge test in all three regression models also implied that the models suffered from heteroskedasticity and autocorrelation problems. To correct these problems, this study therefore analyzed the regression models by using the fixed effect estimation technique with robust standard errors. 
Table 1. Results of panel data regression analysis

\begin{tabular}{|l|l|l|l|}
\hline & Model 1 (R-FE) & Model 2 (R-FE) & Model 3 (R-FE) \\
\hline FDI & $-0.0001 * *(0.0000)$ & $-0.0001 * *(0.0000)$ & $-0.0001 * * *(0.0000)$ \\
\hline TO & $-0.0004 * *(0.0002)$ & $-0.0004^{* *}(0.0002)$ & $-0.0004 * *(0.0002)$ \\
\hline UNE & $-0.0013 * * *(0.0002)$ & $-0.0012^{* * *}(0.0002)$ & $-0.0014 * * *(0.0002)$ \\
\hline INF & $0.0002 * * *(0.0001)$ & $0.0002 * * *(0.0001)$ & $0.0001(0.0001)$ \\
\hline INTR & $0.0009 * * *(0.0000)$ & $0.0010^{* * *}(0.0001)$ & $0.0013^{* * *}(0.0002)$ \\
\hline DLIT & & $0.0002 * * *(0.0000)$ & $0.0008^{* *}(0.0004)$ \\
\hline INTR*DLIT & & & $0.0014^{* *}(0.0005)$ \\
\hline Constant & $0.8039 * * *(0.0119)$ & $0.8010^{* * *}(0.0100)$ & $0.7822^{* * *}(0.0132)$ \\
\hline BP LM test & $187.26^{* * *}[0.000]$ & $153.83 * * *[0.000]$ & $107.38^{* * *}[0.000]$ \\
\hline Hausman test & $45.87 * * *[0.000]$ & $58.89 * * *[0.000]$ & $78.59 * * *[0.000]$ \\
\hline Observations & 152 & 152 & 152 \\
\hline No. of countries & 38 & 38 & 38 \\
\hline R-squared & 0.6999 & 0.7236 & 0.7595 \\
\hline VIF (Multicollinearity) & 1.25 & 1.79 & 13.48 \\
\hline $\begin{array}{l}\text { Modified Wald test } \\
\text { (Heteroskedasticity) }\end{array}$ & $1772.91 * * *$ & $1958.30^{* * *}$ & $3862.66 * * *$ \\
\hline $\begin{array}{l}\text { Wooldridge test } \\
\text { (Serial correlation) }\end{array}$ & {$[0.000]$} & {$[0.000]$} & {$[0.000]$} \\
\hline
\end{tabular}

Notes: Values in parentheses are robust standard errors, whereby $* * *, * *$ and $*$ indicate significance at $1 \%, 5 \%$ and 10\% level, respectively. The corresponding $p$-values for results of preliminary testing (BP LM test and Hausman test) as well as diagnostic checks (Modified Wald test and Wooldridge test) are presented in brackets. Columns denoted by (R-FE) signify that all regression models 1, 2 and 3 are estimated using the robust fixed effect estimator.

In Model 1, all independent variables are found to have significant impact on HDI as their corresponding $p$-values are less than the recommended 5\% significance level. Internet usage - being the main independent variable tested for statistical significance in Model 1 - also revealed to have a significant and positive association with HDI, thus indicating that high levels of Internet usage are crucial in improving human development of the countries. This evidence supports findings by De La Hoz et al. (2019), Ejemeyovwi et al. (2019) and Çaglayan-Akay and Van (2017) who all found similar significant and positive relationship between Internet usage and human development. This study found that 1 percent increase in the share of population using the Internet is associated with a 0.0009 increase in the HDI value. The significance of Internet usage observed in this study further reinforces the need for a substantial increase in Internet usage in order for human development to increase in value as well.

In Model 2, similar set of independent variables in Model 1 are used for this estimation, but with an additional variable representing digital literacy. Alongside other independent 
variables, estimation result of this Model 2 revealed that digital literacy entered with a significant and positive coefficient, which implies at the importance of having essential ICT skills or literacy to progress in this knowledge-driven society and economy. Coefficient values produced by both Internet usage and digital literacy in regression analysis of Model 2 suggest that an increase of 1 percent in Internet users and adults with ICT skills would lead to an increase of 0.001 and 0.0002 in the HDI value, respectively. This result underlines the fact that the pervasive use of ICT makes knowledge of and ability to use ICT as essential requirements for today's critical thinking-workforce, regardless of the type of work being done (Ezziane, 2007). Additionally, in Model 3, a moderation analysis is performed where an interaction term between Internet usage and digital literacy is introduced as part of the independent variables. Interestingly, the interaction effect between Internet users and digital literacy yielded a positive coefficient that is also significant at 5\% significance level. It is also observed that the coefficient of Internet usage in Model 3 has increased to 0.013 as compared to 0.010 in Model 2, which suggests that higher digital literacy skills could strengthen the positive impact of Internet usage on human development. To stay relevant in an economy that is rapidly becoming digital, individuals are not only expected to be able to use and understand technology, but also to have adequate digital literacy to increasingly create and share digital content, building knowledge and solving problems, all while measuring progress (Mizunoya, Mishra, Amaro \& Venturini, 2019).

Considering the control variables introduced in all model estimations, this study found that that all four control variables mostly emerged significant in influencing human development. FDI and trade openness, although significant, entered with unexpected negative coefficients. These finding signals increased competitiveness in the countries, to which both FDI and trade openness contribute, that may result in higher work stress and economic insecurity (Gokmenoglu, Apinran \& Taspinar, 2018). Moreover, unemployment rate produced the expected significant and negative relationship with the HDI, suggesting that lower number of unemployed workers in the total labour force is associated with higher levels of human development. This finding supports that of Clark (2009) who showed that being unemployed may lead to lower subjective well-being and this is established across multiple measures including lower happiness and life satisfaction. Additionally, it is worth noting that inflation is the only control variable that emerged insignificant in Model 3, despite initially entering with significant and positive relationship with human development, both in Model 1 and 2 . The positive coefficient of inflation in Model 1 and 2 suggests that the rise in inflation rate leads to greater human development. Although it is surprising to observe the positive and significant coefficient of inflation, this result is however consistent with that of Yolanda (2017), who also found similar positive relationship between inflation and HDI. The fact that most countries sampled in this study are characterized as growing economies with growing purchasing power, this implies the possible existence of a demand-pull inflation where aggregate demand outpaces aggregate supply, and thus exerts upward pressure on price.

\section{Conclusion and Recommendations}

This study investigated the relationship between digital literacy and human development of 38 countries over the period 2015 to 2018 . Based on the results of preliminary testing, a fixed 
effect estimator with robust standard error was employed to determine the impact of digital literacy and its moderation effect with Internet usage towards human development. This study found that not only Internet usage and digital literacy are individually significant in influencing human development, but their interaction effect also yielded statistically significant and positive relationship with human development. This indicates that improving the levels of Internet usage and digital literacy would lead to greater human development. Additionally, findings of this study imply that while high ICT access and usage are necessary, they are not sufficient conditions for promoting effective usage of digital technology. Rising importance and use of the Internet have made digital literacy a required skill for all. It is imperative to factor in digital literacy when weighing the impact of ICT on human development as adequate digital literacy helps people to exchange ideas, become critical users of information and make informed actions - all in order to participate and thrive in the digital world.

Several policy implication and recommendation can be derived from the findings of this study. In light of the significance of digital literacy found in this study, one of the channels that Internet usage could contribute to human development is through education. Enabling effective and meaningful integration of technology into the usual teaching and learning practice would not only allow students to successfully engage in digital environment, but they may also pick up and develop important digital literacy skills while doing so. Prior to obtaining access to such active online participation, it appears that having sufficient and sound infrastructure play an equally important part as well, since provision of basic infrastructures represent a key element to promote human development of the countries (Amato-Fortes et al., 2017). Therefore, to accelerate usage of the Internet and subsequently promote development of digital literacy among the society, it is therefore recommended that ICT infrastructure be upgraded and expanded in order for the deployment of digital tools to benefit both the society and critical sectors such as education.

Some limitations of this study, however, should be noted. This study particularly focused on Internet usage as the proxy representing ICT development - on which digital literacy was tested for its moderation effect on Internet usage towards human development, while other various indicators measuring technological progress were omitted. The short-run nature of this study may also pose a limitation on the choice of regression estimators used as this study employed only one static panel regression estimator, which is robust fixed effect estimator. Building upon these potential limitations as well as findings of this study, future research may consider examining the influence of other ICT indicators such as fixed broadband subscriptions and households with a computer and Internet access, towards human development. Future research may also cover a relatively longer time period to investigate the long-run impact of digital literacy on human development, which would subsequently allow for a dynamic and more advanced panel data estimation approach such as Instrumental Variables (IV) and Generalized Method of Moments (GMM).

\section{Acknowledgments}

The authors would like to thank the Ministry of Education (MOE) Malaysia and Universiti 
Malaysia Sabah for supporting this work under the Fundamental Research Grant Scheme for Research Acculturation of Early Career Researchers (RACER/1/2019/SS08/UMS/2).

\section{References}

Alazie, G., Devi, R., \& Ebabye, S. (2019). Explore the impact of digital literacy for lifelong learning. International Research Journal of Multidisciplinary Studies, 5(8), 2454-8499.

Alkire, S., \& Deneulin, S. (2009). The Human Development and Capability Approach. In S. Deneulin \& L. Shahani (Eds.), An Introduction to the Human Development and Capability Approach: Freedom and Agency (pp. 22-48). London: Earthscan.

https://doi.org/10.4324/9781849770026

Allison, P. (2012). When Can You Safely Ignore Multicollinearity?. [Online] Available: https://statisticalhorizons.com/multicollinearity (September 10, 2012).

Bahrini, R., \& Qaffas, A. A. (2019). Impact of Information and Communication Technology on Economic Growth: Evidence from Developing Countries. Economies, 7(1), 21.

https://doi.org/10.3390/economies7010021

Bawden, D. (2008). Origins and Concepts of Digital Literacy. In C. Lankshear \& M. Knobel. (Eds.), Digital Literacies: Concepts, Policies and Practices (pp. 17-32). New York: Peter Lang Publishing.

Çağlayan-Akay, E., \& Van, M. H. (2017). Determinants of the Levels of Development based on the Human Development Index: Bayesian ordered probit model. International Journal of Economics and Financial Issue, 7(5), 425-431.

Clark, A. E. (2009). Work, Jobs and Well-Being across the Millennium. IZA Discussion Papers 3940. https://doi.org/10.1093/acprof:oso/9780199732739.003.0014

Coulombe, S., \& Tremblay, Jean-François. (2006). Literacy and Growth. Topics in Macroeconomics, 6(2), 1404. https://doi.org/10.2202/1534-5998.1404

Das, A., Khan, S., \& Chowdhury, M. (2016). Effects of ICT Development on Economic Growth in Emerging Asian Countries. In Dey B., Sorour K. \& Filieri R. (Eds.), ICTs in Developing Countries (pp.141-159). London: Palgrave Macmillan.

https://doi.org/10.1057/9781137469502_9

De La Hoz, B., Camacho-Ballesta, J., Tamayo-Torres, I., \& Buelvas-Ferreira, K. (2019). Effects of information and communication technology usage by individuals, businesses, and government on human development: An international analysis. IEEE Access, 7, 129225-129243. https://doi.org/10.1109/ACCESS.2019.2939404

Ejemeyovwi, J. O., Osabuohien, E. S., Johnson, O. D., \& Bowale, E. I. K. (2019). Internet usage, innovation and human development nexus in Africa: the case of ECOWAS. Journal of Economic Structures, 8(1), 1-16. https://doi.org/10.1186/s40008-019-0146-2

Ezziane, Z. (2007). Information Technology Literacy: Implications on Teaching and Learning. Educational Technology \& Society, 10(3), 175-191. 


\section{Al Macrothink}

Business and Economic Research ISSN 2162-4860 2020, Vol. 10, No. 3

Feldman, M., Hadjimichael, T., Lanahan, L., \& Kemeny, T. (2015). The Logic of Economic Development: A Definition and Model for Investment. Environment and Planning C: Government and Policy, 34(1), 5-21. https://doi.org/10.1177\%2F0263774X15614653

Amate-Fortes, I., Guarnido-Rueda, A., \& Molina-Morales, A. (2017). Economic and Social Determinants of Human Development: A New Perspective. Social Indicators Research, 133(2), 561-577. https://doi.org/10.1007/s11205-016-1389-z

Gilster, P. (1997). Digital Literacy. New York: John Wiley \& Sons Inc.

Gokmen, Y., \& Turen, U. (2013). The determinants of high technology exports volume: A panel data analysis of EU-15 countries. International Journal of Management, Economics and Social Sciences (IJMESS), 2(3), 217-232.

Gokmenoglu, K. K., Apinran, M. O., \& Taspinar, N. (2018). Impact of Foreign Direct Investment on Human Development Index in Nigeria. Business and Economics Research Journal, 9(1), 1-13. https://doi.org/10.20409/berj.2018.90

Hameed, T. (2007). ICT as an enabler of socio-economic development. [Online] Available: https://www.itu.int/osg/spu/digitalbridges/materials/hameed-paper.pdf

Jacobs, G., \& Asokan, N. (2000). Vision 2020: Knowledge for Development. Presentation to the Planning Commission, Government of India. [Online] Available:

http://www.icpd.org/development_strategies/Knowledge\%20for\%20Development.htm

Jose, K. (2016). Digital literacy matters: Increasing workforce productivity through blended English language programs. Higher Learning Research Communication, 6(4).

https://doi.org/10.18870/hlrc.v6i4.354

Karpati, A. (2011). Digital literacy in education. Moscow: UNESCO Institute for Information Technologies in Education. [Online] Available:

http://unesdoc.unesco.org/images/0021/002144/214485e.pdf

Martin, A. (2006). Literacies for the digital age. In A. Martin \& D. Madigan (Eds.), Digital literacies for learning (pp. 3-25). London: Facet Publishing.

https://doi.org/10.29085/9781856049870.003

Mizunoya, S., Mishra, S., Amaro, D., \& Venturini, C. (2019). ICT skills divide: Are all of today's youth prepared for the digital economy?. [Online] Available:

https://blogs.unicef.org/evidence-for-action/ict-skills-divide-todays-youth-prepared-digital-ec onomy/

Muchdie, M. (2016). The Impacts of Technological Progress on Human Development: Evidence from Indonesia. International Journal of Economics and Research, 7(5), 14-28.

Njoku, A. S. (2011). Literacy for Economic Development and Financial Restitude. International Journal of Environmental Science and Development, 2(1), 24-26. https://doi.org/10.7763/IJESD.2011.V2.91

Ricardo, D. (1817). On the Principles of Political Economy and Taxation. London: John 
Murray.

Roser, M. (2014). Human Development Index (HDI). [Online] Available:

https://ourworldindata.org/human-development-index

Schumpeter, J. A. (1962). The Theory of Economic Development: An Inquiry into Profits, Capital, Credit, Interest, and the Business Cycle. Cambridge: Harvard University Press.

Sen, A. (1985). Commodities and Capabilities. Amsterdam: Oxford University Press.

Sen, A. (1999). Development as Freedom. Oxford: Oxford University Press.

Smith, A. (1776). An Inquiry into the Nature and Causes of the Wealth of Nations. New York: Modern Library. https://doi.org/10.1093/oseo/instance.00043218

Solow, R. M. (1956). A contribution to the theory of economic growth. The Quarterly Journal of Economics, 70(1), 65-94. https://doi.org/10.2307/1884513

Suharyanto, C., \& Gunawan, F. (2015). The Role of Information Communication \& Technology as Enabler of Knowledge Management Process to Bring Innovation in Creative Industries (Batam Case). Proceeding of the 1st International Conference on Character Education, 329-337.

Toader, E., Firtescu, B., Roman, A., \& Anton, S. (2018). Impact of Information and Communication Technology Infrastructure on Economic Growth: An Empirical Assessment for the EU Countries. Sustainability, 10(10), 3750. https://doi.org/10.3390/su10103750

United Nations Development Programme (UNDP). (1990). Human Development Report 1990: Concept and Measurement of Human Development. [Online] Available: http://www.hdr.undp.org/en/reports/global/hdr1990

United Nations. (2015). Transforming Our World: The 2030 Agenda for Sustainable Development. New York: UN Publishing.

Vega, V. (2011). Digital Literacy is the Bedrock for Lifelong Learning. [Online] Available: https://www.edutopia.org/blog/digital-divide-technology-internet-access-literacy-vanessa-veg a

Yolanda, Y. (2017). Analysis of Factors Affecting Inflation and its Impact on Human Development Index and Poverty in Indonesia. European Research Studies Journal, 20(4), 38-56. https://doi.org/10.35808/ersj/873

\section{Copyright Disclaimer}

Copyright for this article is retained by the author(s), with first publication rights granted to the journal.

This is an open-access article distributed under the terms and conditions of the Creative Commons Attribution license (http://creativecommons.org/licenses/by/4.0/). 